\title{
Significant enhancement of photoresponsivity in As-doped n-BaSi 2 epitaxial films by atomic hydrogen passivation
}

Sho Aonuki ${ }^{1}$, Yudai Yamashita ${ }^{1}$, Takuma Sato ${ }^{1,2}$, Zhihao Xu${ }^{1}$, Kazuhiro Gotoh ${ }^{3}$, Kaoru Toko ${ }^{1}$, Yoshikazu Terai ${ }^{4}$, Noritaka Usami ${ }^{3}$ and Takashi Suemasu ${ }^{1}$

${ }^{1}$ Institute of Applied Physics, University of Tsukuba, Tsukuba, Ibaraki 305-8573, Japan

${ }^{2}$ Université Grenoble Alpes, CNRS, CEA, INAC-SyMMES, 38000 Grenoble, France

${ }^{3}$ Graduate School of Engineering, Nagoya University, Nagoya 464-8603, Japan

${ }^{4}$ Department of Computer Science and Electronics, Kyushu Institute of Technology, Iizuka, Fukuoka 820-8502, Japan

Corresponding author:

Takashi Suemasu, University of Tsukuba

suemasu@bk.tsukuba.ac.jp 
We grew $500 \mathrm{~nm}$-thick lightly arsenic (As)-doped n-BaSi 2 epitaxial films at $600{ }^{\circ} \mathrm{C}$ by molecular beam epitaxy, and supplied atomic hydrogen $(\mathrm{H})$ in the duration $\left(t_{\mathrm{BaSi}: \mathrm{H}}\right)$ of $0-30 \mathrm{~min}$, followed by capping with a $3 \mathrm{~nm}$-thick amorphous Si layer at $180^{\circ} \mathrm{C}$. The photoresponsivity of the $\mathrm{BaSi}_{2}$ films was enhanced by approximately five times by As doping. Deep level transient spectroscopy measurement revealed the disappearance of previously reported two electron traps. The photoresponsivity was further enhanced by approximately six time after the H supply. It reached a maximum at $t_{\mathrm{BaSi}: \mathrm{H}}=1-10 \mathrm{~min}$, owing to the reduction of defects. 
Photovoltaics (PV) systems have been globally deployed and reached a cumulative installed capacity of over $500 \mathrm{GWp}$ in 2018. It is necessary to further deploy PV systems to establish a sustainable energy supply. Crystalline Si solar cells now account for approximately $90 \%$ of the market, ${ }^{1)}$ and its conversion efficiency $(\eta)$ steadily increased beyond $26 \%$ at the research stage. ${ }^{2)}$ Thin-film solar cell materials such as cadmium telluride, chalcopyrite, and perovskite have also been attracting attention because of their cost effective growth procedure and high $\eta$ beyond $22 \% .^{3-8)}$ Thin-film Si has also been studied for years by utilizing an efficient light trapping systems. ${ }^{9-11)}$ Under such circumstances, we have paid special attention to barium disilicide $\left(\mathrm{BaSi}_{2}\right) .{ }^{12,13)} \mathrm{BaSi}_{2}$ consists of earth-abundant $\mathrm{Si}$ and $\mathrm{Ba}$, and has attractive features ${ }^{12,13)}$ such as a suitable band gap of $1.3 \mathrm{eV}$, a large optical absorption coefficient $(\alpha)$ of $3 \times 10^{4} \mathrm{~cm}^{-1}$ at $1.5 \mathrm{eV}$, and a large minority carrier diffusion length $(\sim 10 \mu \mathrm{m})$, which is larger than the grain size of $\mathrm{BaSi}_{2}$. We have achieved $\eta$ approaching $10 \%$ in $\mathrm{p}-\mathrm{BaSi}_{2} / \mathrm{n}-\mathrm{Si}$ heterojunction solar cells ${ }^{14,15)}$ and recently demonstrated the operation of $\mathrm{BaSi}_{2}$ homojunction solar cells. ${ }^{16)} \mathrm{We}$ are now focusing on the improvement of optical properties of $\mathrm{BaSi}_{2}$ light absorber layers. According to firstprinciples calculation, $\left.{ }^{17}\right) \mathrm{Si}$ vacancies $\left(\mathrm{V}_{\mathrm{Si}}\right)$ are most likely to occur among point defects in $\mathrm{BaSi}_{2}$, and generate deep localized states within the band gap, which act recombination centers. Defect characterizations of $\mathrm{BaSi}_{2}$ have been conducted by deep level transient spectroscopy (DLTS $){ }^{18,19)}$ positron annihilation spectroscopy, ${ }^{20,21)}$ Raman spectroscopy, ${ }^{22)}$ photoluminescence, ${ }^{23)}$ and electron paramagnetic resonance. ${ }^{24)}$ By using these techniques, we detected defects, most of which are considered $\mathrm{V}_{\mathrm{Si}}$. As a measure to investigate the optical properties of $\mathrm{BaSi}_{2}$ films, we have used photoresponsivity because it is very sensitive to carrier lifetime. Our previous research shows that the photoresponsivity of undoped $\mathrm{BaSi}_{2}$ films is enhanced markedly by supplying atomic hydrogen $(\mathrm{H})$ produced by an radio-frequency (RF) plasma generator after the growth of $\mathrm{BaSi}_{2}$ films for 15 min owing to the increase of carrier lifetime, proved by microwave-detected photoconductivity decay measurement ( $\mu$-PCD). ${ }^{25)}$ This result means that defects in undoped $\mathrm{BaSi}_{2}$ films are passivated by atomic $\mathrm{H}$. As the basic structure of a solar cell is a pn-junction, it is thereby necessary to examine whether or not defects in impurity-doped $\mathrm{n}-\mathrm{BaSi}_{2}$ and $\mathrm{p}-\mathrm{BaSi}_{2}$ films are passivated by atomic $\mathrm{H}$. Regarding B-doped $\mathrm{p}$ $\mathrm{BaSi}_{2}$ films, the effect of $\mathrm{H}$ passivation was very recently demonstrated. ${ }^{26)}$ On the other hand, there has been no report on the effect of atomic $\mathrm{H}$ on As-doped $\mathrm{n}-\mathrm{BaSi}_{2}$ films. The valence band maximum of $\mathrm{BaSi}_{2}$ is mainly composed of $\mathrm{Si} \mathrm{s}$ and $\mathrm{p}$ orbitals. ${ }^{27,28)}$ Therefore, substitution of $\mathrm{Si}$ 
atoms in $\mathrm{BaSi}_{2}$ with group 15 elements such as As increases the valence electron concentration and forms n-BaSi ${ }_{2}{ }^{29)}$ We adopted GaAs granules as a source of As rather than elemental As. It is possible to supply only As from GaAs thanks to a much lower vapor pressure of Ga than that of As. ${ }^{30)}$ Furthermore, As atoms are supplied in the form of As 2 from GaAs, and are thus more likely to decompose into As atoms than that of As4 emitted from elemental As. ${ }^{31)}$

We fabricated lightly As-doped n-BaSi 2 epitaxial films by MBE. An ion-pumped MBE system equipped with an RF plasma generator for atomic $\mathrm{H}$, an electron-beam gun for $\mathrm{Si}$, and Knudsen cells for $\mathrm{Ba}$ and $\mathrm{GaAs}$ was used. $\mathrm{Si}(111)$ substrates were employed for $a$-axis-oriented As-doped $\mathrm{n}-\mathrm{BaSi}_{2}$ epitaxial films. The detailed growth method of As-doped $\mathrm{BaSi}_{2}$ epitaxial films has been reported previously. ${ }^{32)}$ Briefly, after cleaning the $\mathrm{Si}(111)$ substrates, we formed a $\mathrm{BaSi}_{2}$ template layer by reactive deposition epitaxy, in which only Ba was supplied to a heated $\mathrm{Si}$ substrate. This template layer works as a seed crystal for overlayers. Next, a $500 \mathrm{~nm}$-thick Asdoped $\mathrm{BaSi}_{2}$ epitaxial layer was formed by $\mathrm{MBE}$ at a substrate temperature $\left(T_{\mathrm{S}}\right)$ of $600{ }^{\circ} \mathrm{C}$. We set the temperature of GaAs granules at $300{ }^{\circ} \mathrm{C}$, because the photoresnponsivity of As-doped $\mathrm{BaSi}_{2}$ films reached a maximum at around this temperature. ${ }^{32)}$ The As concentration $\left(N_{\mathrm{As}}\right)$ in the As-doped $\mathrm{BaSi}_{2}$ films was below the limit of detection by secondary ion mass spectrometry (SIMS) $\left(N_{\mathrm{As}}<5 \times 10^{17} \mathrm{~cm}^{-3}\right)$. We also fabricated an undoped $\mathrm{BaSi}_{2}$ film for comparison. After that, atomic $\mathrm{H}$ was supplied at $T_{\mathrm{S}}=600{ }^{\circ} \mathrm{C}$ to As-doped $\mathrm{BaSi}_{2}$ films with various supply durations $t_{\mathrm{BaSi}} \mathrm{H}$ of $0,1,10,15,20$, and $30 \mathrm{~min}$. The plasma power was set at $10 \mathrm{~W}$. The flow of atomic $\mathrm{H}$ was controlled by a vacuum gauge of the MBE system; the vacuum level was $1.0 \times$ $10^{-3} \mathrm{~Pa}$ during the $\mathrm{H}$ supply. Finally, a 3-nm-thick amorphous Si capping layer was formed in situ at $T_{\mathrm{S}}=180^{\circ} \mathrm{C}$ to prevent surface oxidation. We used Czochralski (CZ)-p-Si(111) substrates $(\rho>1000 \Omega \mathrm{cm})$ for $\mu$-PCD and Raman spectroscopy measurements. On the other hand CZ- ${ }^{+}-$ $\operatorname{Si}(111)$ substrates $(\rho<0.01 \Omega \mathrm{cm})$ were used for photoresponsivity and DLTS measurements. For this purpose, front surface electrodes with 1-mm-diameter $80 \mathrm{~nm}$-thick ITO and back surface electrodes with $150 \mathrm{~nm}$-thick $\mathrm{Al}$ were formed by sputtering. We evaluated the optical properties with a lock-in technique using a xenon lamp (Bunko Keiki, SM-1700A) and a single monochromator with a focal length of $25 \mathrm{~cm}$ (Bunko Keiki, RU-60N) under a bias voltage ( $V_{\text {bias}}$ ) of -0.3 or $-0.5 \mathrm{~V}$ to the surface ITO electrodes with respect to the rear $\mathrm{Al}$ electrodes. The intensity of incident light was calibrated with a pyroelectric sensor (Melles Griot, 13PEM001/J). Excess-carrier decay kinetics were evaluated by a $\mu$-PCD measurement system (Kobelco, LTA- 
1512EP). Carriers were generated by a $5 \mathrm{~ns}$ laser pulse with a wavelength of $349 \mathrm{~nm}(3.55 \mathrm{eV})$. The excitation power was $1.3 \times 10^{5} \mathrm{Wcm}^{-2}$. Photoconductivity decay was measured using the reflectivity of a microwave with a frequency of $26 \mathrm{GHz}$. Polarized Raman spectra were collected to investigate local vibrational modes $(\mathrm{LVM})$ at the $X(Y Z) \bar{X}$ geometry of the typical Porto notation using a polarizer. The $X$-axis was parallel to $\mathrm{BaSi}_{2}$ [100]. In this geometry, the most intense Raman peak of the $\operatorname{Ag}$ mode $\left(488 \mathrm{~cm}^{-1}\right)$ can be suppressed since there are only the diagonal constitution of Raman tensor of the $\mathrm{Ag}$ mode ${ }^{33)}$ so that LVM at around $490 \mathrm{~cm}^{-1}$ can be observed. DLTS measurement was performed at 80-300 K. A 1 MHz capacitance-voltage meter (HP 4280A) was used. All measurements except DLTS were carried out at room temperature.

The $a$-axis-oriented epitaxial growth of all the samples was confirmed by reflection highenergy electron diffraction and $\theta-2 \theta$ X-ray diffraction. The hole concentration of undoped $\mathrm{p}$ $\mathrm{BaSi}_{2}$ films was $8.7 \times 10^{15} \mathrm{~cm}^{-3}$ and the electron concentration of As-doped $\mathrm{n}-\mathrm{BaSi}_{2}$ films was $7.1 \times 10^{16} \mathrm{~cm}^{-3}$. Figure 1(a) shows the photoresponse spectra of undoped $\mathrm{p}-\mathrm{BaSi}_{2}$ and As-doped $\mathrm{n}-\mathrm{BaSi}_{2}$ films. The photoresponsivity was obtained at wavelengths smaller than approximately $1000 \mathrm{~nm}$, corresponding to the band gap of $\mathrm{BaSi}_{2}$. The photoresponsivity was apparently improved by As doping. This result is interpreted to originate from the decrease of defects such as $\mathrm{V}_{\mathrm{Si}}$ because doped As atoms are considered to occupy part of $\mathrm{V}_{\mathrm{Si}}$ in the films. The photoresponsivity of As-doped $\mathrm{BaSi}_{2}$ films was further improved by atomic $\mathrm{H}$ supply and reached a maximum at $t_{\mathrm{BaSi}: \mathrm{H}}=1$ and $10 \mathrm{~min}$ as shown in Fig. 1(b), wherein the $\mathrm{H}$ concentration was of the order of $10^{18}-10^{19} \mathrm{~cm}^{-3}{ }^{25)}$ The highest photoresponsivity was approximately six times higher than that of As-doped $\mathrm{BaSi}_{2}$ films without atomic $\mathrm{H}$ supply. The photoresponsivity in the short wavelength range $(\lambda=300-450 \mathrm{~nm})$ was the highest at $t_{\mathrm{BaSi}: \mathrm{H}}=1 \mathrm{~min}$, and degraded with increasing $t_{\mathrm{BaSi}: \mathrm{H}}$. Since the $\alpha$ of $\mathrm{BaSi}_{2}$ in such short $\lambda$ exceeds $5 \times 10^{5} \mathrm{~cm}^{-1},{ }^{12)}$ the penetration depth of the light is estimated to be less than $3 / \alpha \sim 60 \mathrm{~nm}$, meaning that short- $\lambda$ photons are absorbed in the surface region of $\mathrm{BaSi}_{2}$ films. This result thereby suggests that the surface of $\mathrm{BaSi}_{2}$ films was damaged by atomic $\mathrm{H}$ supply. Similar results were obtained for undoped $\mathrm{BaSi}_{2}$ films after the $\mathrm{H}$ supply. ${ }^{25)}$ At $t_{\mathrm{BaSi}: \mathrm{H}} \geq 15 \mathrm{~min}$, however, the photoresponsivity started to degrade. On the other hand, in undoped $\mathrm{BaSi}_{2}$ films, the photoresponsivity reached a maximum at $t_{\mathrm{BaSi}: \mathrm{H}}=$ 15 min. $^{25)}$ It is noted that the photoresponsivity reached a maximum at a shorter value of $t_{\mathrm{BaSi}} \mathrm{H}$ (1-10 min) for As-doped $\mathrm{BaSi}_{2}$ films than that for undoped $\mathrm{BaSi}_{2}$ films $\left(t_{\mathrm{BaSi}: \mathrm{H}}=15 \mathrm{~min}\right)$. We speculate that the reason for this is that the density of $\mathrm{V}_{\mathrm{Si}}$ is smaller in As-doped $\mathrm{BaSi}_{2}$ films than 
in undoped $\mathrm{BaSi}_{2}$ films, and thus a smaller amount of $\mathrm{H}$ atoms are enough to passivate $\mathrm{V}_{\mathrm{Si}}$ in Asdoped $\mathrm{BaSi}_{2}$ films.

According to the significant improvement of the photoresponsivity of the atomic $\mathrm{H}$ passivated $\mathrm{BaSi}_{2}$ films, it is reasonable to consider that the carrier lifetime would be improved for these samples. Figure 2 shows the photoconductivity decay curves. Assuming that the reflectivity of microwaves is proportional to the excess carrier concentration, we can deduce the carrier lifetime from the decay curves. The areal photon density was $\left(1.3 \times 10^{5} \times 5 \times 10^{-9}\right) /(1.6 \times$ $\left.10^{-19} \times 3.55\right) \approx 1.1 \times 10^{15} \mathrm{~cm}^{-2}$. The photogenerated carrier concentration is thus calculated to be $1.1 \times 10^{15} /\left(0.5 \times 10^{-4}\right)=2.2 \times 10^{19} \mathrm{~cm}^{-3}$ on average, assuming that photogenerated carriers are uniformly distributed over the $500 \mathrm{~nm}$-thick As-doped $\mathrm{BaSi}_{2}$ films. Hara et al. illustrated that the decay curves of $\mathrm{BaSi}_{2}$ films can be fitted by three exponential functions. ${ }^{34)}$ The first rapid decay curve originates from the Auger recombination, the second decay from the Shockley-Read-Hall $(\mathrm{SRH})$ recombination, and the third one from the SRH recombination accompanying carrier traps. Following this method, we fitted the experimentally obtained curves with dashed lines. Here we define $\tau_{1 / e}$ as the time when the reflected microwave intensity decreases by $\exp (-1)$ of the initial value after the excitation laser was turned off. As shown in Fig. 2, $\tau_{1 / e}$ was determined to be approximately $0.1,0.8,2.7,2.8$, and $1.6 \mu \mathrm{s}$, respectively, at $t_{\mathrm{BaSi}: \mathrm{H}}=0,1,10,20$, and $30 \mathrm{~min}$. The $\tau_{1 / e}$ rapidly increased with $t_{\mathrm{BaSi}: \mathrm{H}}$ and almost saturated at around $t_{\mathrm{BaSi}: \mathrm{H}}=10-20 \mathrm{~min}$, and then decreased for $t_{\mathrm{BaSi}: \mathrm{H}}>20 \mathrm{~min}$. The general trend seen in Fig. 2, that is, $\tau_{1 / e}$ increases with $t_{\mathrm{BaSi}: \mathrm{H}}$, becomes maximum at a certain value of $t_{\mathrm{BaSi}: \mathrm{H}}$, and decreases for longer $t_{\mathrm{BaSi}: \mathrm{H}}$, is the same as that observed for the photoresponsivity against $t_{\mathrm{BaSi}: \mathrm{H}}$ in Fig. 1(b). However, the optimum $t_{\mathrm{BaSi}: \mathrm{H}}$ differs between photoresponsivity and $\tau_{1 / e}$. We speculate that this disagreement comes from a large difference in a measurement area between the two measurement methods; an area of $1 \times 1$ $\mathrm{cm}^{2}$ was used for $\mu$-PCD, while only a $1 \mathrm{~mm}$-diameter area was for photoresponsivity. Therefore, $\tau_{1 / e}$ is more likely to be affected by nonuniformity of samples.

To understand the effect of As doping in more detail, we performed the DLTS measurement on As-doped n-BaSi 2 films. Regarding the trap levels in undoped $\mathrm{BaSi}_{2}$ films, two electron trap levels positioned at approximately 0.1 and $0.2 \mathrm{eV}$ from the conduction band minimum (CBM) were detected previously. ${ }^{18,19)}$ Figure 3 (a) shows the DLTS profiles of the Asdoped $\mathrm{n}-\mathrm{BaSi}_{2}$ film at $t_{\mathrm{BaSi}: \mathrm{H}}=0 \mathrm{~min}$. The forward filling pulse voltage $V_{\mathrm{P}}$ with a pulse width 
$t_{\mathrm{pw}}=50 \mathrm{~ms}$ was set at $0.5 \mathrm{~V}$, and the reverse bias voltage $V_{\mathrm{R}}$ was varied as $-0.1,-0.5$, and $-1.0 \mathrm{~V}$. Because of a large difference in electron concentration $(n)$ between $\mathrm{n}^{+}-\mathrm{Si}\left(n>5 \times 10^{18} \mathrm{~cm}^{-3}\right)^{35)}$ and As-doped $\mathrm{n}-\mathrm{BaSi}_{2}\left(n \sim 7.1 \times 10^{16} \mathrm{~cm}^{-3}\right)$, the depletion region stretches towards the $\mathrm{n}-\mathrm{BaSi}_{2}$ side. A downward facing peak due to a majority carrier (electron) trap (E1) was detected at around $200 \mathrm{~K}$. The peak intensity decreased with increasing $\left|V_{\mathrm{R}}\right|$, meaning that the traps were positioned around the heterointerface. Figure 3(b) shows the Arrhenius plots of the thermal emission rates $\left(T^{2} / e_{\mathrm{n}}^{\mathrm{t}}\right)$ of captured electrons, where $e_{\mathrm{n}}^{\mathrm{t}}$ is the thermal emission rate and the $T$ is the absolute temperature. ${ }^{36)}$ The calculated energy levels $E 1$ were $0.79,0.80$, and $0.98 \mathrm{eV}$ from the $\mathrm{CBM}$ at $V_{\mathrm{R}}=-0.1,-0.5$, and $-1.0 \mathrm{~V}$, respectively. As the As-doped n-BaSi2 films showed higher photoresponsivity than undoped ones, we ascribe such deep levels $(0.8-0.9 \mathrm{eV})$ not to actual defects but to a conduction band offset of approximately $0.8 \mathrm{eV}$ at the $\mathrm{BaSi}_{2} / \mathrm{Si}$, caused by a difference in electron affinity between $\mathrm{Si}(4.05 \mathrm{eV})$ and $\operatorname{BaSi}_{2}(3.2 \mathrm{eV}) .{ }^{37)}$ There have been several reports thus far on the detection of band offsets by DLTS for heterointerfaces such as $\mathrm{Si} / \mathrm{SiGe}$ and GaAs/InGaAs. ${ }^{38-40)}$ Considering this way, we conclude that the two electron trap levels previously reported decreased significantly by As doping and fell below the limit of detection. As the electron concentration of As-doped n-BaSi 2 films is $7.1 \times 10^{16} \mathrm{~cm}^{-3}$, the trap density is considered to be smaller than $10^{15} \mathrm{~cm}^{-3}$. We attribute the defect reduction to doped As atoms occupying part of $\mathrm{V}_{\mathrm{Si}}$.

Regarding the experimentally obtained further enhancement of photoresponsivity in Asdoped $\mathrm{BaSi}_{2}$ films by $\mathrm{H}$ supply, there is a lack of information about the position of atomic $\mathrm{H}$ in the lattice of As-doped $\mathrm{BaSi}_{2}$. According to ab initio electronic property simulations of $\mathrm{BaSi}_{2}$ with $\mathrm{V}_{\mathrm{Si}}$ and $\mathrm{H}$ incorporation, $\mathrm{V}_{\mathrm{Si}}$ becomes inactive when two $\mathrm{H}$ atoms are in a $\mathrm{V}_{\mathrm{Si}}{ }^{25)}$ Therefore, we speculate that $\mathrm{H}$ atoms are also around $\mathrm{V}_{\mathrm{Si}}$ in As-doped $\mathrm{BaSi}_{2}$ films. Figure 4 shows the Raman shift of the Ag mode deduced from polarized Raman spectra of As-doped $\mathrm{BaSi}_{2}$ films at $t_{\mathrm{BaSi}: \mathrm{H}}=0-30 \mathrm{~min}$. Typical examples of polarized Raman spectra at $t_{\mathrm{BaSi}: \mathrm{H}}=0$ and $1 \mathrm{~min}$ are also shown. One Lorentzian curve at around $488 \mathrm{~cm}^{-1}$ is enough to reconstruct the measured spectrum at $t_{\mathrm{BaSi}: \mathrm{H}}=0 \mathrm{~min}$. However, another Lorentzian curve located at around $493 \mathrm{~cm}^{-1}$ is necessary to reconstruct the spectrum at $t_{\mathrm{BaSi}: \mathrm{H}}=1 \mathrm{~min}$. Similar results were obtained for other samples at $t_{\mathrm{BaSi}: \mathrm{H}} \geq 10 \mathrm{~min}$. This is the reason why the peak position of the Raman shift was higher than that at $t_{\mathrm{BaSi}: \mathrm{H}}=0 \mathrm{~min}$. The origin of this new peak is unknown at present; however, there is a 
possibility that reflects the bonding of $\mathrm{H}$ to a $\mathrm{Si}$ atom in $\mathrm{Si}$ tetrahedra of the $\mathrm{BaSi}_{2}$ lattice. To identify the origin of this peak, it is necessary to investigate the atomic structure of Si tetrahedral by using first-principles calculation in the near future.

We fabricated As-doped n-BaSi2 films by $\mathrm{MBE}$ at $T_{\mathrm{S}}=600{ }^{\circ} \mathrm{C}$ and investigated the effect of atomic $\mathrm{H}$ supply on their photoresponsivity. The photoresponsivity was enhanced by As doping compared to undoped $\mathrm{BaSi}_{2}$ films. DLTS measurement revealed that the defect density of previously reported two electron traps fell below the detection limit of SIMS. The photoresponsivity was further enhanced by approximately six times when the atomic $\mathrm{H}$ was supplied on As-doped $\mathrm{BaSi}_{2}$ films for $1-10 \mathrm{~min}$ at $T_{\mathrm{S}}=600{ }^{\circ} \mathrm{C}$. When the atomic $\mathrm{H}$ supply duration lengthened further, the photoresponsivity decreased. These results showed the atomic $\mathrm{H}$ supply is an effective means to passivate the defects in As-doped n-BaSi ${ }_{2}$ films and enhance their photoresponsivity.

\section{Acknowledgements}

This work was financially supported by JSPS KAKENHI Grant Numbers $18 \mathrm{H} 01477$ and 18H03767. One of the authors (Y. Y.) was financially supported by Grant-in-Aid for JSPS Fellows (19J21372). 


\section{Captions of figures}

Fig. 1 Photoresponse spectra of (a) undoped and As-doped $\mathrm{BaSi}_{2}$ films at $V_{\text {bias }}=-0.5 \mathrm{~V}$, and (b) As-doped $\mathrm{BaSi}_{2}$ films grown with different values of $t_{\mathrm{BaSi}: \mathrm{H}}=0-30 \mathrm{~min}$ at $V_{\text {bias }}=-0.3 \mathrm{~V}$. All the samples were grown at $T_{\mathrm{S}}=600{ }^{\circ} \mathrm{C}$ for As doping.

Fig. 2 Photoconductivity decay curves of As-doped $\mathrm{BaSi}_{2}$ films grown with different values of $t_{\mathrm{BaSi}: \mathrm{H}}=0-30 \mathrm{~min}$. The fitting lines are shown as dashed lines.

Fig. 3 (a) DLTS profiles obtained for $n-\mathrm{BaSi}_{2} / \mathrm{n}-\mathrm{Si}$ diodes on the $\mathrm{CZ} \mathrm{n}^{+}-\mathrm{Si}(111)$ substrate. The forward filling pulse voltage $V_{\mathrm{P}}$ was set at $0.5 \mathrm{~V}$ with a pulse width of $t_{\mathrm{pw}}=50 \mathrm{~ms}$, and the reverse-bias voltage $V_{\mathrm{R}}$ was set at $-0.1,-0.5$, and $-1.0 \mathrm{~V}$. The rate window was varied as $1-32$, 2-64, 4-128, 8-256, and 16-512 ms. (b) Arrhenius plots of the thermal emission rates $\left(T^{2} / e_{\mathrm{n}}^{\mathrm{t}}\right)$ for electron trap level $(E 1)$ observed for As-doped n-BaSi2 films at $V_{\mathrm{R}}=-0.1,-0.5$, and $-1.0 \mathrm{~V}$. Here, $e_{\mathrm{n}}^{\mathrm{t}}$ is the thermal emission rate and $T$ is the absolute temperature.

Fig. 4 Raman shift of the Ag mode as a function of $t_{\mathrm{BaSi}: \mathrm{H}}$ for As-doped $\mathrm{BaSi}_{2}$ films obtained for polarized Raman spectra at the $X(Y Z) \bar{X}$ geometry. Typical examples of the spectra for samples grown with $t_{\mathrm{BaSi}: \mathrm{H}}=0$ and $1 \mathrm{~min}$ are shown. The fitting lines are shown as dashed lines. 


\section{References}

1) M. A. Green, E. D. Dunlop, D. H. Levi, J. Hohl-Ebinger, M. Yoshita, and A. W. Y. Ho-Baillie, Prog. Photovoltaics Res. Appl. 27, 565 (2019).

2) K. Yoshikawa, H. Kawasaki, W. Yoshida, K. Konishi, K. Nakano, T. Uto, D. Adachi, M. Kakematsu, H. Uzu, and K. Yamamoto, Nat. Energy 2, 17032 (2017).

3) J. Britt and C. Ferekides, Appl. Phys. Lett. 62, 2851 (1993).

4) A. Romeo, A. Terheggen, D. Abou-Ras, D. L. Batzner, F. J. Haug, M. Kalin, D. Rudmann, and A. N. Tiwari, Prog. Photovoltaics 12, 93 (2004).

5) X. Wu, Sol. Energy 77, 803 (2004).

6) I. Repins, M. A. Contreras, B. Egaas, C. DeHart, J. Scharf, C. L. Perkins, B. To, and R. Noufi, Prog. Photovoltaics 16, 235 (2008).

7) H. Katagiri, K. Jimbo, W. S. Maw, K. Oishi, M. Yamazaki, H. Araki, and A. Takeuchi, Thin Solid Films 517, 2455 (2009).

8) P. Jackson, R. Wuerz, D. Hariskos, E. Lotter, W. Witte, and M. Powalla, Phys. Status Solidi Rapid Research Lett. 10, 583 (2016).

9) D. Zhou and R. Biswas, J. Appl. Phys. 103, 093102 (2008).

10) A. Hongsingthong, T. Krajangsang, I. A. Yunaz, S. Miyajima, and M. Konagai, Appl. Phys. Express 3, 051102 (2010).

11) H. Sai, Y. Kanamori, and M. Kondo, Appl. Phys. Lett. 98, 113502 (2011).

12) T. Suemasu, Jpn. J. Appl. Phys. 54, 07 JA01 (2015).

13) T. Suemasu and N. Usami, J. Phys. D. Appl. Phys. 50, 023001 (2017).

14) S. Yachi, R. Takabe, H. Takeuchi, K. Toko, and T. Suemasu, Appl. Phys. Lett. 109, 072103 (2016).

15) T. Deng, T. Sato, Z. Xu, R. Takabe, S. Yachi, Y. Yamashita, K. Toko, and T. Suemasu, Appl. Phys. Express 11, 062301 (2018).

16) K. Kodama, Y. Yamashita, K. Toko, and T. Suemasu, Appl. Phys. Express 12, 041005 (2019).

17) M. Kumar, N. Umezawa, W. Zhou, and M. Imai, J. Mater. Chem. A 5, 25293 (2017).

18) H. Takeuchi, W. Du, M. Baba, R. Takabe, K. Toko, and T. Suemasu, Jpn. J. Appl. Phys. 54, 07JE01 (2015). 
19) Y. Yamashita, T. Sato, N. Saitoh, N. Yoshizawa, K. Toko, and T. Suemasu, J. Appl. Phys. 126, 215301 (2019).

20) Y. Yamashita, Y. Takahara, T. Sato, K. Toko, A. Uedono, and T. Suemasu, Appl. Phys. Express 12, 055506 (2019).

21) A. Montes, S. W. Eijt, Y. Tian, R. Gram, H. Schut, T. Suemasu, N. Usami, M. Zeman, J. Serra, and O. Isabella, J. Appl. Phys. 127, 085304 (2020).

22) T. Sato, H. Hoshida, R. Takabe, K. Toko, Y. Terai, and T. Suemasu, J. Appl. Phys. 124, 025301 (2018).

23 ) T. Sato, Y. Yamashita, Z. Xu, K. Toko, S. Gambarelli, M. Imai, and T. Suemasu, Appl. Phys. Express 12, 111001 (2019).

24) T. Sato, C. Lombard, Y. Yamashita, Z. Xu, L. Benincasa, K. Toko, S. Gambarelli, and T. Suemasu, Appl. Phys. Express 12, 061005 (2019).

25) Z. Xu, D. A. Shohonov, A. B. Filonov, K. Gotoh, T. Deng, S. Honda, K. Toko, N. Usami, D. B. Migas, V. E. Borisenko, and T. Suemasu, Phys. Rev. Mater. 3, 065403 (2019).

26) L. Benincasa, Z. Xu, T. Deng, T. Sato, K. Toko, and T. Suemasu, Jpn. J. Appl. Phys. 59, SFFA08 (2020).

27) Y. Imai and A. Watanabe, Intermetallics 15, 1291 (2007).

28) D. B. Migas, V. L. Shaposhnikov, and V. E. Borisenko, Phys. Status Solidi B 244, 2611 (2007).

29) K. O. Hara, N. Usami, M. Baba, K. Toko, and T. Suemasu, Thin Solid Films 567, 105 (2014).

30) J. R. Arthur, J. Phys. Chem. Solids 28, 2257 (1967).

31) C. T. Foxon, J. A. Harvey, and B. A. Joyce, J. Phys. Chem. Solids 34, 1693 (1973).

32) S. Aonuki, Y. Yamashita, K. Toko, and T. Suemasu, Jpn. J. Appl. Phys. 59, SFFA01 (2020).

33) H. Hoshida, N. Murakoso, T. Suemasu, and Y. Terai, Defect Diffus. Forum 386, 43 (2018).

34) K. O. Hara, N. Usami, K. Toh, M. Baba, K. Toko, and T. Suemasu, J. Appl. Phys. 112, 083108 (2012).

35) S. M. Sze, Physics of Semiconductor Devices (Wiley, New York, 1981) $2^{\text {nd }}$ ed.

36) D. V. Lang, J. Appl. Phys. 45, 3023 (1974).

37) T. Suemasu, K. Morita, M. Kobayashi, M. Saida, and M. Sasaki, Jpn. J. Appl. Phys. 45, L519 (2006).

38) L. Vescan, R. Apetz, and H. Lüth, J. Appl. Phys. 73, 7427 (1993). 
39) L. Lu, J. Wang, Y. Wang, W. Ge, G. Yang, and Z. Wang, J. Appl. Phys. 83, 2093 (1998).

40) L. Lu, S. Su, C. C. Ling, S. Xu, D. Zhao, J. Zhu, H. Yang, J. Wang, and W. Ge, Appl. Phys. Express 5, 091001 (2012). 


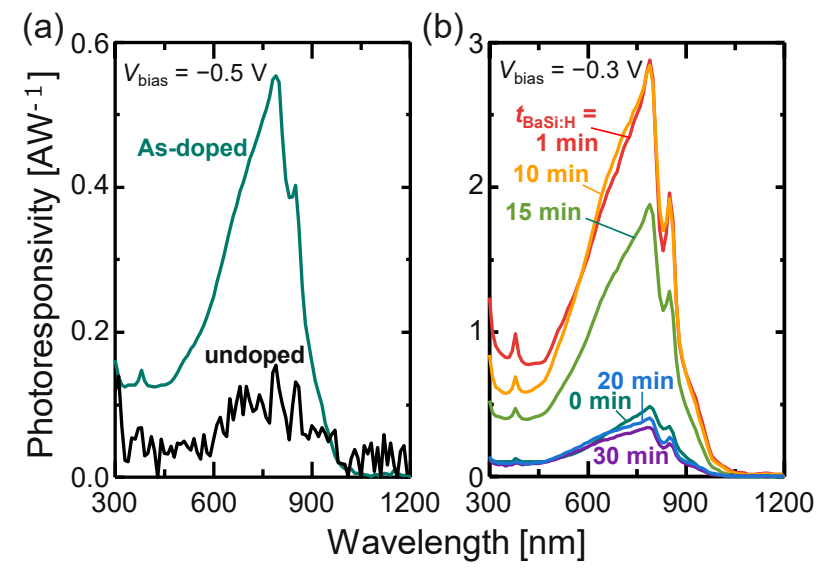

Fig. 1 


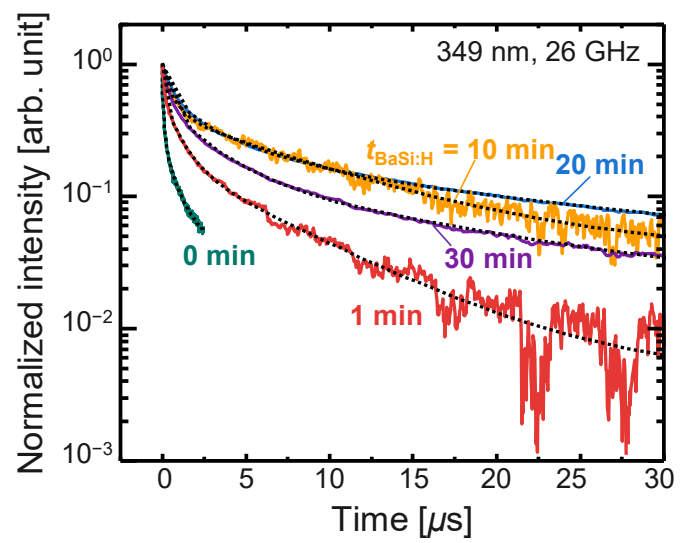

Fig. 2 
(a) $\quad V 450 \mathrm{~ms}$
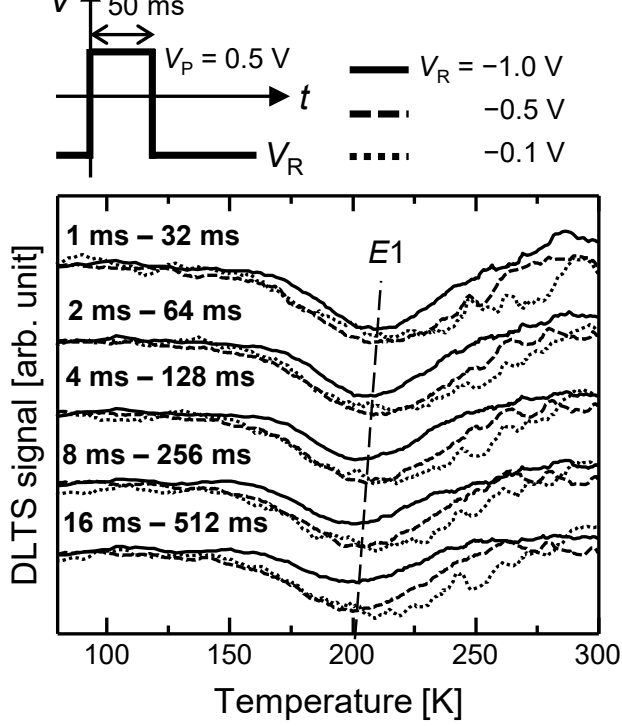

(b)

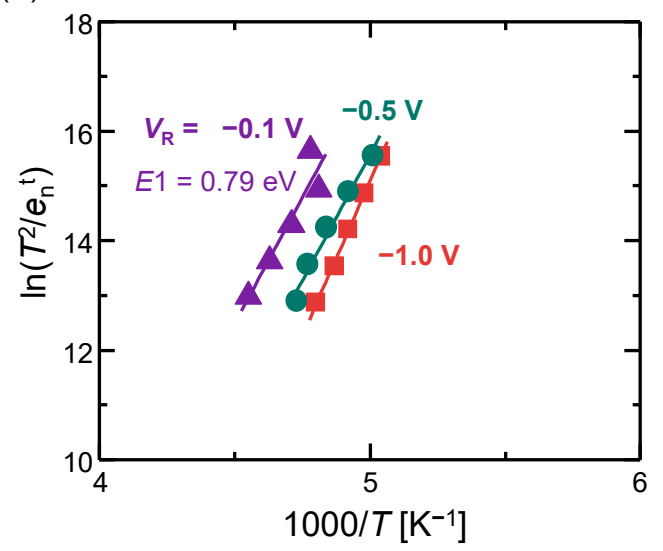

Fig. 3 


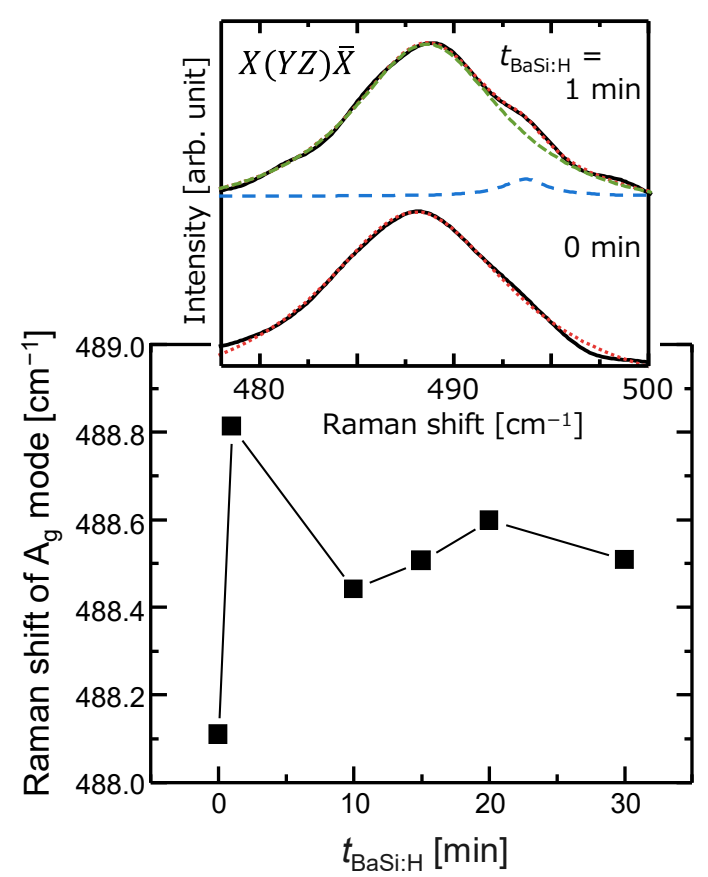

Fig. 4 